\title{
Endovascular abdominal aortic aneurysm repair and embolization of a pararenal aneurysm
}

\author{
Tratamento de aneurisma da aorta abdominal com implante \\ de endoprótese e embolização de saco aneurismático justacolo
}

Abdo Farret Neto', Antônio Anderson Fernandes Freire², Márcio Villar de Freitas

\section{INTRODUCTION}

Juxtarenal or pararenal aneurysms begin at the level of the renal arteries and do not afford a large enough neck for conventional endovascular treatment ${ }^{1,2}$. Unfavorable anatomy is responsible for a large proportion of technical failures, such as mal-positioned or dislodged stents, leading to type I endoleaks ${ }^{3}$. In such cases special strategies are needed to ensure endovascular treatment success ${ }^{4}$.

\section{PART I - CLINICAL SITUATION}

The patient was a 64-year-old sedentary male smoker with hypertension, diabetes and chronic obstructive pulmonary disease (COPD) with a forced expiratory volume in 1 second $\left(\mathrm{VEF}_{1.0}\right)$, less than $60 \%$ of predicted capacity. An infrarenal abdominal aortic aneurysm with a $4.8 \mathrm{~cm}$ diameter was diagnosed by Doppler ultrasound. On physical examination, the patient's general condition was regular, the abdominal aorta was hyperpulsatile and the left pedal pulse was absent, although all other pulses were present and symmetrical. Since the AAA diameter was less than $5.5 \mathrm{~cm}$ at this consultation, the patient was given advice on lifestyle habit changes, such as walking and giving up smoking. The medication he was already on was maintained (atenolol, enalapril and metformin) and a return appointment for ultrasound examination was scheduled for 6 months later.

At the return consultation, Doppler ultrasound showed that the aneurysm had increased in size by $6 \mathrm{~mm}$ in five and a half months, and had a $5.4 \mathrm{~cm}$ diameter. Angiotomography (Angio-TC) was requested and showed a secondary aneurysm sac in a pararenal position (Figure 1). This second aneurysm sac, located $7 \mathrm{~mm}$ from the right renal artery, introduced an additional difficulty since there was now a risk of the stent becoming dislodged into it.

\section{PART II - WHAT WAS DONE}

The decision was taken to repair the aneurysm using endovascular methods in view of the patients' pulmonary capacity and the fact that he did not consent to conventional surgery. An Apolo ${ }^{\circledR}$ $25 \times 12 \times 12 \times 150$ branched stent (Nano Endoluminal, Florianópolis, Brazil) with double proximal free flow and a $12 \times 12 \times 110$ straight-line length was implanted via a right femoral access. The pararenal saccular aneurysm was embolized with $12 \times 14$ and $10 \times 14$ Nester ${ }^{\circledR}$ coils (Cook Medical Inc. Bloomington, IN, USA) after the main body of the stent had been released. However, the coils had been placed in advanced, using a Vertebral $5 \mathrm{~F}$ catheter via a left femoral access and left ready in the sac of the pararenal aneurysm before release of the main body of the stent (Figure 2). After the secondary pararenal aneurysm had been completely filled with coils, the procedure was completed with placement of the left iliac branch and fixation with a 20-50×100 Coda balloon (Cook Medical Inc. Bloomington, IN, USA) (Figure 3).

Control angiographs showed that the procedures had been successful, with excellent patency of the system and obliteration of both aneurysms, with no evidence of endoleaks (Figure 4).

The patient coursed progressed with no intercurrent conditions and an angio-CT performed eighth months after the procedure showed that exclusion

\footnotetext{
'Hospital do Coração de Natal - HCN, Endovasc, Natal, RN, Brazil.

${ }^{2}$ Universidade Federal do Rio Grande do Norte - UFRN, School of Medicine, Natal, RN, Brazil.

Financial support: None.

Conflicts of interest: No conflicts of interest declared concerning the publication of this article.

Submitted on: 07.31.13. Accepted on: 08.13.13.
}

Study carried out at Hospital do Coração de Natal. 


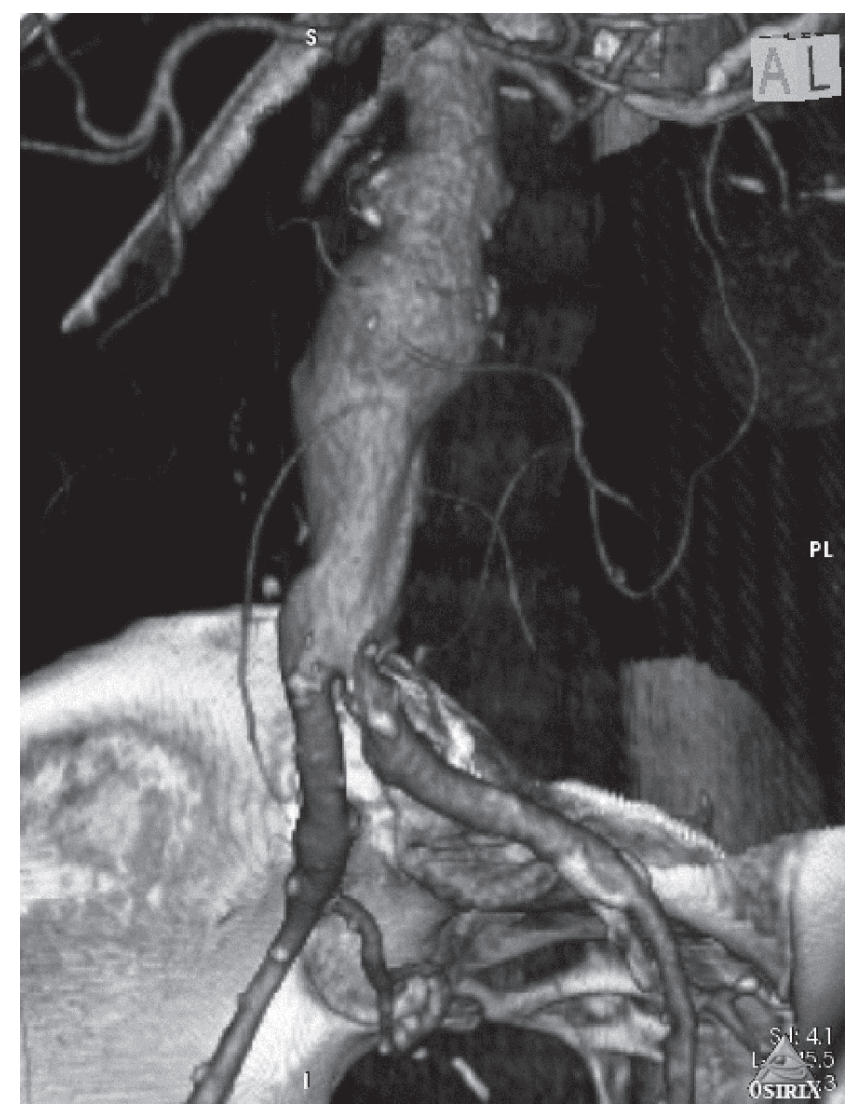

Figure 1. Angio-CT showing the secondary pararenal aneurysm sac.



Figure 2. Intraoperative angiography showing the pararenal sac (A). In (B), the released main body of the stent can be seen compressing the vertebral catheter against the aorta wall. The catheter tip is inside the pararenal aneurysm sac. 


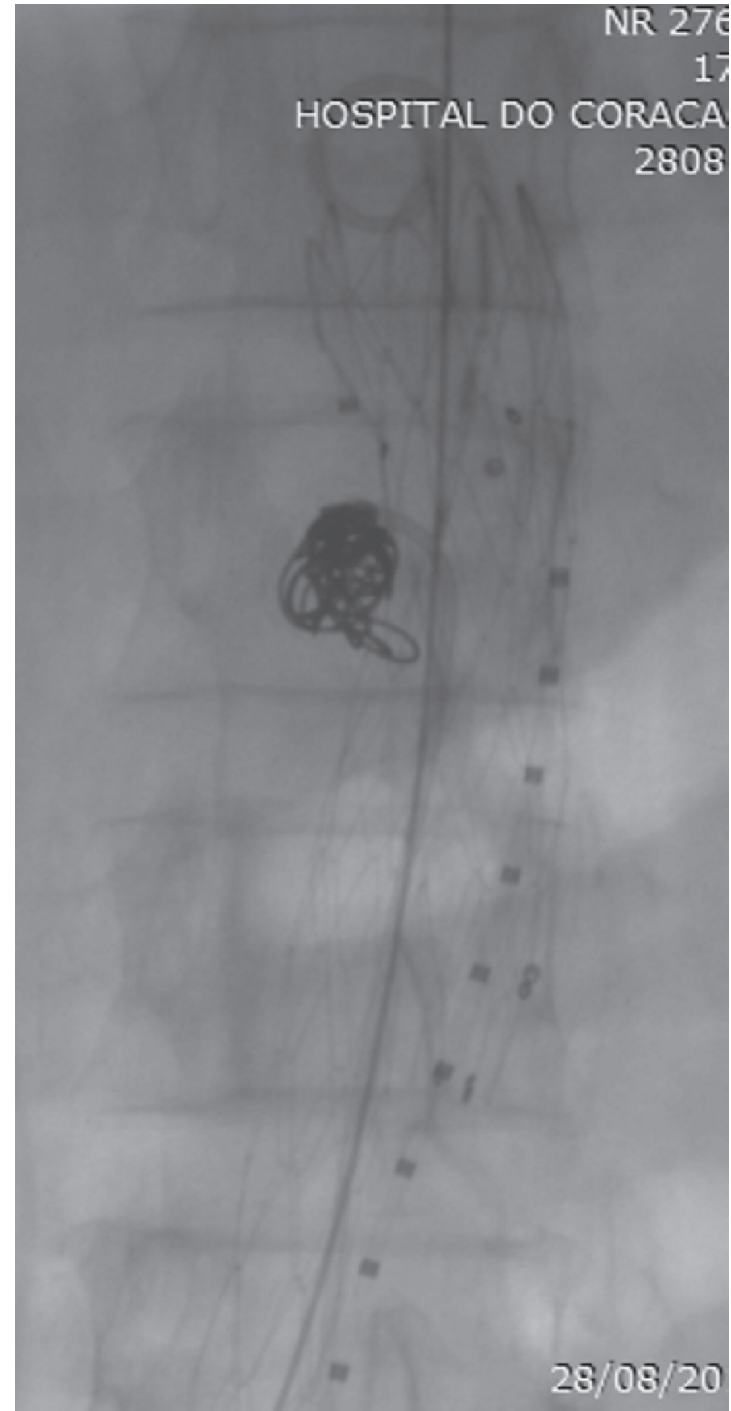

Figure 3. Observe the pararenal sac filled with coils.

of the primary and secondary aneurysmal sacs had been maintained, and the primary sac diameter had reduced to $4.4 \mathrm{~cm}$ (Figure 5).

\section{DISCUSSION}

Treatment of abdominal aorta aneurysms with endovascular methods, described in 1991 for the first time by Parodi ${ }^{5}$, is becoming ever more common. Despite the complexity of the procedure, the dependence on favorable anatomy and the need for a highly trained technical team, the minimally invasive character of the procedure and its advantages for postoperative recovery have promoted it to the treatment of first choice, wherever indicated.

In the case described here, the secondary pararenal aneurysm sac created an additional therapeutic

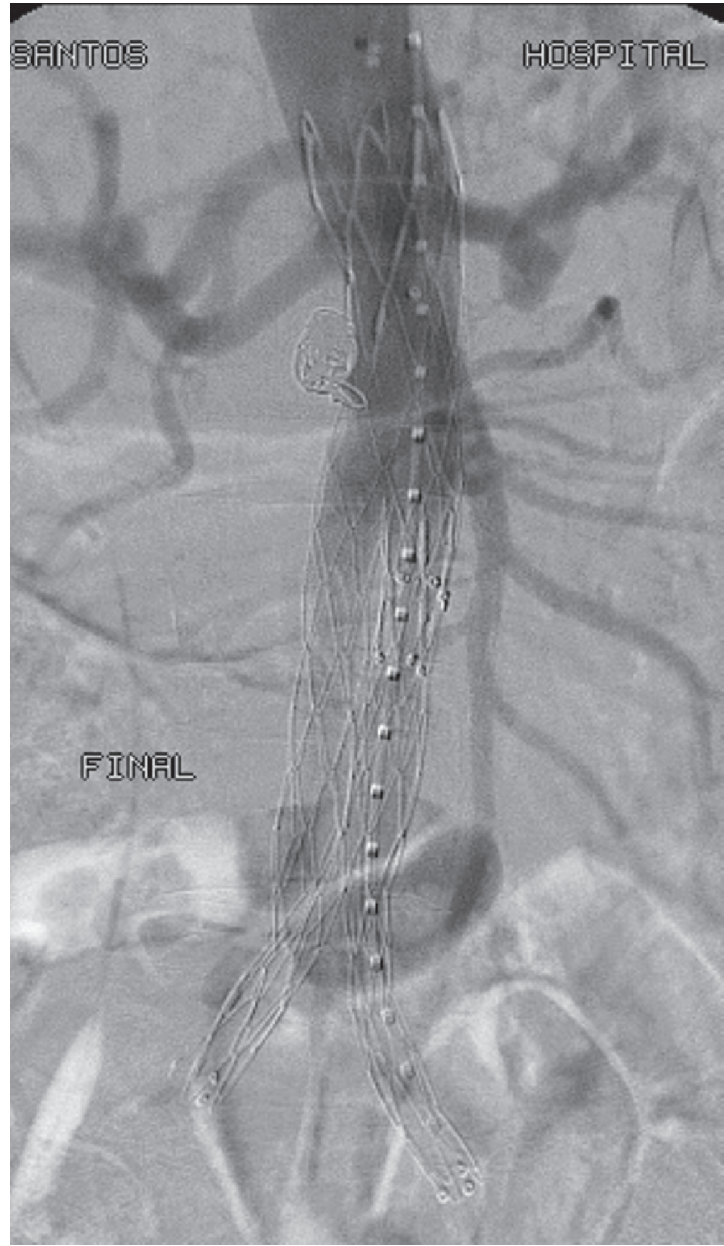

Figure 4. Final intraoperative appearance. Observe obliterated aneurysms and absence of endoleaks.

challenge. Another challenge was to avoid a type I endoleak, in view of the short neck. These difficulties were surmounted by customizing an stent with double proximal free flow, in order to provide better support for fixation, and by filling the proximal aneurysm sac with coils. This was achieved using the strategy of placing the tip of a vertebral $5 \mathrm{~F}$ diagnosis catheter inside the sac before the main body of the stent was released. After the main body had been released into its pararenal position and the right common iliac artery branch had been placed, the coils were released inside the secondary sac until it was entirely filled. Next the catheter was removed and the left common iliac artery branch of the stent was placed conventionally and the procedure finished off. We used the main body of the stent to retain the coils inside the secondary sac, since it had a wide neck. In one recently reported case ${ }^{1}$, the author used a selfexpanding stent accomplish this function, followed 


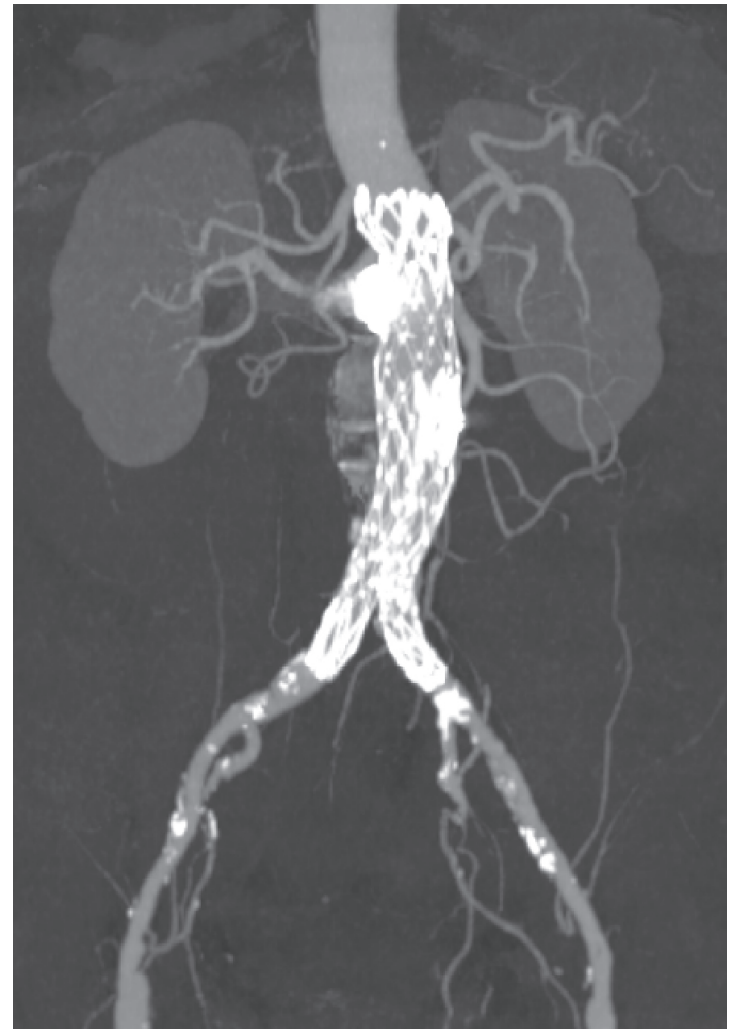

Figure 5. Angio-TC demonstrating that exclusion of primary and secondary aneurysmal sac exclusion has been maintained and showing coils inside the pararenal sac.

by placement of a stent, which made the proximal neck into a 'sandwich' comprising stent and stent. Among other possibilities, a multilayer stent ${ }^{6,7}$ or fenestrated stents ${ }^{8}$ could have been used, but at the time we did not feel sufficiently familiarized with these techniques.

The patient is asymptomatic with renal function spared and a recent tomographic study showed that the treatment employed achieved and maintained the stated objectives, namely to exclude both aneurysm sacs with no endoleaks and with shrinkage of the primary sac diameter.

\section{REFERENCES}

1. Sarac TP, Clair DG, Hertzer NR, et al. Contemporary results of juxtarenal aneurysm repair. J Vasc Surg. 2002;36(6):1104-11. PMid:12469040. http://dx.doi.org/10.1067/mva.2002.129638

2. Jongkind V, Yeung KK, Akkersdijk GJ, et al. Juxtarenal aortic aneurysm repair. J Vasc Surg. 2010;52(3):760-7. PMid:20382492. http://dx.doi.org/10.1016/j.jvs.2010.01.049

3. Coscas F, Becquemin JP, Majewski M, et al. Management of Perioperative Endoleaks During Endovascular Treatment of Juxta-Renal Aneurysms. Ann Vasc Surg. 2012;26(2):175-84. PMid:22078306. http://dx.doi.org/10.1016/j.avsg.2010.10.021
4. Mendonça CT, Carvalho CA, Wein J. The Use of a Self-expandable Aortic Stent to Incarcerate Microcoils and to Create a Favourable Infrarenal Neck in an Unusual Case of Endovascular Abdominal Aortic Aneurysm Repair. Eur J Vasc Endovasc Surg. 2013 May;45(5):465-7. PMid:23473782. http://dx.doi.org/10.1016/j. ejvs.2013.01.040

5. Parodi JC, Palmaz JC, Barone HD. Transfemoral Intraluminal Graft Implantation for Abdominal Aortic Aneurysms. Ann Vasc Surg. 1991;5(6):491-9. PMid:1837729. http://dx.doi.org/10.1007/ BF02015271

6. Pieper CC, Meyer C, Verrel F, et al. Using the Multilayer Stent as a Supplement to EVAR in Combined Abdominal Aortic Aneurysm and Iliac Artery Aneurysm With Inadequate Distal Landing Zone-A Case Report. Vasc Endovasc Surg. 2012;46(7):565-9. http://dx.doi.org/10.1177/1538574412456306

7. Henry M, Polydorou A, Frid N, et al.. Treatment of renal artery aneurysm with the multilayer stent. J Endovasc Ther. 2008;15(2):231-6. PMid:18426265. http://dx.doi. org/10.1583/07-2222.1

8. Verhoeven EL, Vourliotakis G, Tielliu IF, et al. Fenestrated Stent grafting for short-necked and justarenal abdominal aortic aneurysm: An 8-year single-centre experience. Eur J Vasc Endovasc Surg. 2010;39(5):529-36. PMid:20202868. http://dx.doi. org/10.1016/j.ejvs.2010.01.004

Correspondence

Abdo Farret Neto

Rua Dr. Múcio V. Ribeiro Dantas, 500 E/27 - Ponta Negra CEP 59092-580 - Natal (RN), Brazil E-mail: abdo.farret@gmail.com

Author's information

AFN is Angiologist, vascular surgeon and angioradiologist, Member, Colégio Brasileiro de Cirurgia (TCBC) and Sociedade Brasileira de Angiologia e Cirurgia Vascular (TSBACV), Angioradiologist, Hospital Universitário Onofre Lopes, is Professor of Cardiovascular System Diseases at Universidade Federal do Rio Grande do Norte (UFRN) and is PhD candidate, Drug Development and Technological Innovation - UFRN

AAFF is Medical student, Universidade Federal do Rio Grande do Norte (UFRN)

MVF is Lato sensu degree in Vascular Surgery, Sociedade Brasileira de Angiologia e Cirurgia Vascular and Vascular surgeon, Hospital Universitário Onofre Lopes, Natal-RN.

Author's contributions Conception and design: AFN Analysis and interpretation: AFN Data collection: AAFF

Writing the article: AAFF, AFN Critical revision of the article: MVF Final approval of the article*: AFN, AAFF, MVF Statistical analysis: N/A Overall responsibility: AFN Obtained funding: None.

* All authors have read and approved of the final version of the article submitted to I Vasc Bras. 